\title{
Writing at the Interface: A Research and Teaching Program for Everyday Digital Media Literacy
}

\author{
Matthew Overstreet - Khalifa University
}

\section{KEYWORDS}

networked literacy; digital media literacy; design thinking; interface studies; new materialism; writing pedagogy; information ecosystems; information management

\author{
"The twenty-first-century arts are the arts of interface." \\ - Malcolm McCullough, Ambient Commons
}

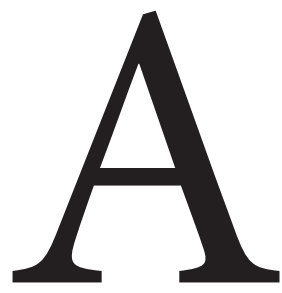

t noon on May 21, 2016, two groups of activists squared off outside the Islamic Da'wah Center in Houston, Texas. One group, bearing Confederate flags and "White Lives Matter" t-shirts, was there to protest the "Islamization" of Texas. They'd been called to action via "The Heart of Texas," a popular right- wing Facebook group. Their opponents, Muslim Americans and their allies, were also responding to a call issued via Facebook, in their case by "United Muslims of America." According to the Houston Chronicle, counter-protestors outnumbered protestors five to one, and the event, though tense, was peaceful (Glenn).

Was the Houston showdown just another example of the power of digital technology to further connection and cooperation, for good or ill? It certainly seemed so until eighteen months later, when it was revealed that, in fact, both "The Heart of Texas" and "United Muslims of America" were operated by foreign agents. Over the course of many months, group members on both sides were fed a steady diet of twisted and outright false information (in addition to some accurate information, and numerous jokes and memes, of course). The event in Houston was the culmination of this programming, an attempt to convert online tribalism into real-world political action. "What neither side could have known," said Senator Richard Burr, "was that Russian trolls were encouraging both sides to battle in the streets and create division between real Americans" (Bertrand). Burr's claim is striking. Note how he positions the participants, though: neither side could have known. Is this accurate? Could the participants really not have known they were being manipulated? In short, I believe that they could and should have known. As a society, we have an obligation to ensure that they know. And as writing teachers and literacy scholars, we can help fulfill this obligation. To do so effectively, though, we need a more robust understanding of our current information environment 
and what literacy in such a space might entail. In the following pages, I will attempt to articulate such an understanding.

I make several intertwining claims. First, I argue that composition studies should do more to understand and promote networked literacy as it manifests in everyday digital media engagement patterns. With smart phones and broadband internet, media-as in digitally mediated informationpermeates every aspect of our lifeworld. Like those of the protestors in Texas, our students' habitual engagements shape how they think, write, read and relate. Digital media habits thus impact what happens in the writing classroom. Writing teachers need to recognize and respond to this new (mediated) reality.

Second, I argue that to understand everyday digital media literacy, we need to think the human and non-human in combination. When we engage the world through digital media, our tools shape our perception, thought and action. But tools never act alone. Recent writing studies scholarship has done much to illuminate the complex ways in which human and non-human intertwine in literacy activity. From this scholarship, I draw a set of concepts that I believe can help theorize everyday digital media literacy. In particular, I urge attention to the design of information ecosystems, defined as patterns of mediated connection that help shape how individuals determine what is good, true, and possible. These systems are accessible via the interface, where we encounter networks, algorithms, flows and bots, but also human minds and bodies. In practical terms, approaching literacy via the interface means we foreground the ways in which human thought and behavior are influenced (but never determined) by the design of our tools. Insights from design studies, as well as the work of media theorist W. James Potter, I argue, can assist with such a project.

After using interface analysis to better understand the events in Houston, I turn to the classroom. At the interface, most literacy behaviors are automated and habituated. They occur outside the realm of conscious thought. With this in mind, the focus of literacy instruction shifts from "fact-checking" or other goal-directed activity to the habitual patterns of connection that form one's information ecosystem. Using my classroom as an example, I argue that writing teachers can help students design healthy information ecosystems by encouraging study of digital literacy practices. By making students aware of their behaviors at the interface-and giving them the opportunity to evaluate and adjust those behaviors-writing teachers can help students both write better and avoid digital manipulation. ${ }^{1}$

\section{Networked Individualism}

With the dawning of the digital age, followed quickly by the mobile revolution and Web 2.0, writing studies scholars have naturally turned their attention to the digital. Surprisingly, though, discussions of what might constitute digital literacy, and the relationship of writing instruction to such a literacy/literacies, remain few and far between. From the New London Group, writing teachers know that literacy is a social practice, that it is always contextual and multifaceted. We know that literacies inevitably involve production as well as consumption, and that we must assiduously avoid the "great divide" (for an overview, see Brandt and Clinton). Within composition proper, perhaps 
the most in-depth attempt to provide a pedagogically workable definition of digital literacy can be found in Stuart Selber's Multiliteracies for a Digital Age from 2004. Here, Selber provides a three-part taxonomy for a "computer multiliteracies program" (25). He argues that students need functional literacy, critical literacy, and rhetorical literacy; they should be able to understand computers as tools, cultural artifacts, and "hypertextual media," respectively (25). Ten years later, Mary K. Stewart, in an insightful yet little-cited webtext, proposed a similar framework. To be digitally literate, she argues, students need to be skilled in multimodal composition and also able to manage the dynamics of information flows and online collaboration. We see in these competing frameworks a movement outward, from "computer literacy" to "networked literacy." This movement continues in a 2017 special issue of Literacy in Composition Studies on literacy, democracy, and fake news, introduced by Thomas Miller and Adele Leon. Spurred by the impact of misinformation on the 2016 US presidential election, contributions - some of which are discussed below-wrestle with what it might mean to understand (and teach) literacy as a networked phenomenon.

The current essay helps further theorize networked literacies. It is informed by the belief that the cultivation of such literacies is essential to social wellbeing. As such, it reflects the ideals captured in the NCTE's position statement entitled "Definition of Literacy in a Digital Age." This document, first published in 2008 and last updated in 2019, holds that contemporary literacy includes the ability to use technology to build relationships and share information, in order to "solve problems collaboratively and strengthen independent thought" (National). In order to help students achieve this way of being, I'd argue, we first need a deep understanding of the socio-techno space teachers and students now inhabit. Close attention to "how we live now" can help us better understand both misinformation efforts and how we might conceive of and teach networked literacy.

The work of sociologist Barry Wellman is instructive. Wellman argues that over the past halfcentury, human social relations have moved from being centered around small, tightly knit groups (what he calls "little boxes") to being centered around more diffuse and far-flung social networks. Though the pace and scope of this movement varies, Wellman finds it is occurring on a global scale, driven both by changing social mores and steady technological advance. In this new social landscape, each individual is expected to act as the central node in their own personalized network. No longer embedded in stable groups, in other words, individuals now have to build and manage their own set of social relations. In this world of "networked individualism," Wellman writes, "the person has become the portal" (14).

The changes in our "social operating system" noted by Wellman manifest on a number of levels. Relationships are now more selective, driven by interest rather than obligation. Interactions are also more likely to be electronically mediated. Combined with a proliferation of information sources, the result is a massive increase in information exposure (Baron). With more information comes more responsibility. Rather than relying on gatekeepers, such as church, family or editorial board, each networked individual is expected to develop their own complex system of filters and sorting mechanisms. ${ }^{2}$ Sources will likely include both interpersonal and institutional data streams. As Lee Rainie and Barry Wellman put it, networked individuals must constantly "exploit the networked information available to them according to their assessments of what is most beneficial and 
efficient for their needs" (232). Because it demands a relatively more active approach to others and information, Rainie and Wellman hold that networked individualism is both "socially liberating and socially taxing" (9).

Raine and Wellman sketch a relational landscape that is likely familiar. Via a variety of digital tools, we keep in contact with a diffuse constellation of friends and acquaintances. We create and maintain relationships based on our needs and interests and, in turn, understand the world through these self-selected contacts. Our perception, in other words, is shaped not only by what is directly accessible to the senses but by our patterns of mediated connection. It is easy to forget the unique nature of this situation. As Mark Deuze puts it, as networked individuals we exist in a "mediapolis ... a comprehensively mediated public space where media underpin and overarch the experiences and expressions of everyday life" (137). According to Deuze, we live in, rather than with, media. Ironically, as media becomes more and more pervasive, it is rendered increasingly invisible. The steady merger of our tools and our consciousness leads to an "increasing immateriality of one's experience of society" (Deuze 143), but at the same time, a feeling that one is more "in touch" or "connected" than ever.

Networked individualism, a life lived in media-this, in short, is the social operating system that the agents who organized the Houston protests were able to exploit. The members of "The Heart of Texas" and "United Muslims of America" joined these groups voluntarily, as networked individuals pursuing individual interests (solidarity, entertainment). Through measured but repeated doses of digital misinformation, their "experience of society" was tweaked and twisted, until, in Houston, the mediated erupted into the material.

Though relatively small in scale, the Houston event is an important artifact. It acts as a tangible reminder of the dangers unsophisticated tool use pose to democratic politics and reminds us that poor practice is not necessarily an issue of political affiliation. Indeed, people on both sides of the political spectrum were fooled. The Houston event also shows the wide-reaching impact of everyday digital media activity. Of late, some scholars have argued we've entered an age of media convergence, in which distinctions between reading and writing, text and image, virtual and actual, have collapsed (see Jenkins; within writing studies see Purdy; Williams). I agree. And I argue that given the world sketched by Wellman and Deuze (my world), the distinction between digital media activity and the traditional concerns of the writing classroom has also collapsed. The digitally mediated web each individual weaves - whom we connect with and how we connect-shapes how we understand and engage. Though the literacy behaviors that constitute this space are often decidedly non-academic, taken together, they provide the knowledge and experience out of which our students create academic essays, and poems, and lab reports, and everything else. As such, to teach writing, I'd argue, must be to teach—at least to an extent-everyday digital media literacy. ${ }^{3}$

\section{New Materialism and Beyond}

In the previous section, I argued that due to social and technological change, it is no longer practical to teach writing without considering how non-academic literacy behaviors in general, 
and digital media engagement patterns in particular, shape what and how we write. Networked individuals live in media. They use complex, highly personalized systems of "filters and sorting mechanisms" to carve reality out of the mediated flux. Taken together, these filters and mechanisms constitute an individual's "networked literacy." How might we best understand them? Of late, literacy studies, like the humanities in general, has undergone something of a material turn. While the social construction of literacy practices remains an object of inquiry, scholars have also come to recognize, to paraphrase Laura Micciche, that matter matters. As such, within the composition literature we find detailed studies of the relationship between literacy and place (e.g. Prior and Shipka; Rule), tools (e.g. Ching; Hass), and ecologies of all sorts (e.g. Hawisher et. al.; Syverson). This work can be grouped under the label of "new materialism."

All told, I believe that materialist approaches are essential to understanding and teaching everyday digital media literacy. In the world of networked individualism, humans and tools are intimately entwined. We understand our world through phones and Facebook and myriad invisible algorithms. Therefore, any literacy program must respect the non-human. Fortunately, the composition literature contains a rich array of resources we can draw on to theorize the relationship between tools and selves. In this section, I would like to forward three concepts that I believe are particularly potent: the information ecosystem, the interface, and the user as designer. Taken together, these ideas can form the core of a research and teaching program for everyday digital media literacy.

While the first concept - the information ecosystem - is new to our field, ecological theories of writing have a long history (see Cooper). Such theories have gained traction of late for their unique ability to theorize the multiplicity of actors-both human and non-human-involved in the writing process. According to Antonio Byrd, an ecological approach to writing starts from the premise that each writer is "enmeshed in ... a complex, constantly evolving system of relationships between the social and the material" (32). Byrd deploys such an approach to trace the singular "networks of support" African American computer programming students use to facilitate their literacy learning. My claim is that a similar lens can be used to think patterns of mediated connection. As Jacob Craig notes, when used in discussions of information literacy, the ecosystem metaphor hints at the dynamic, ever-shifting nature of networked information. It hints at the multiplicity of agents involved in information creation and distribution and the extent to which they are mutually defining. In an age of metastasized media, remember, individuals both act and are acted upon, create and consume. They use tools, discourse and social networks and are used by these entities. The idea that we each read, write and think from within our own highly personalized information ecosystem is thus central to understanding networked literacy.

The second concept I want to forward is that of the interface. For our purposes, the interface is the space where the human and non-human meet. It is the point where design - as in the arrangement of form-is actualized. As with ecological metaphors, references to the interface are not new to writing studies. Scholars in the area of computers and composition, in particular, have a long history of considering the impact of design on human minds and bodies (see Selfe and Selfe; Wysocki and Jasken). Kristen Arola, for example, in a 2010 essay, analyzes the competing constructions of self afforded by various social media platforms. In doing so, she models attention to what she calls the 
"rhetoric of the interface." Digital literacy, Arola suggests, begins when we attend to the ways in which "interfaces are shaping our interactions and ourselves" (7).

Of late, scholars in the new materialist mold have followed Arola in seeking to trace the impact of design. Erika Sparby, for instance, examines the ways in which the design of 4Chan, an anonymous internet message board, guides the formation of user identity. Integrally, Sparby's analysis attends to more than just 4Chan's layout or appearance. Instead, she studies this tool's functionality, for instance, the fact that the site demands anonymity and does not archive content. The "technological design of an interface-manifested through the actions it allows or prevents-has just as much power, if not more, in constructing a collective identity as the users do," Sparby determines (87). Here we see simultaneous attention to both non-human and human, to both tools and their impact. Indeed, tools are understood through their impact. Approaching literacy activity via the interface, in other words, allows Sparby to capture the practical interaction of human and non-human in information systems. Interface analysis thus emerges as a powerful means to theorize everyday digital media literacy.

The third concept I'd like to forward focuses attention on the human component of information assemblages. At the interface, digital media users read, write, watch, share, etc. In an age of media convergence, these activities often blur together. What common attribute do they share? Tanya Rodrigue provides an answer. Drawing on the work of the influential New London Group (1996), Rodrigue suggests that digital media engagement itself is an act of design. Rodrigue's object of interest is digital reading, which she argues "is best positioned as a design-oriented activity, a meaningmaking process" that involves combining multiple genres and modes (236, emphasis in original). This formulation draws attention to the inherently active nature of digital media use. Though the interface is a built environment, meaning here is never given; instead users must construct it out of a disparate mix of elements (text, image, shape, shade, etc.). Rodrigue is primarily interested in how users might combine elements at a single site, such as when reading a webpage. I would suggest, though, that her concept of user as designer can be productively expanded to capture multiple modes of engagement spread over time and space. To stay connected and informed, users design information ecosystems. They design identities and relationships and knowledge structures. In all cases, this process involves combining disparate forms as to make meaning, either for self or other. It involves carving legibility out of the mediated flux.

Understanding digital media engagement as design has numerous implications. Perhaps most importantly, it informs how we should think about the relationship between literacy practices and theory, rules or other forms of abstract knowledge. According to the New London Group, while design always draws on shared resources, any specific act of design is utterly singular. As Richard Marback puts it, design problems are "wicked," in that their solutions are always highly contextdependent, often turning on "visceral reactions," that can be "elicited and guided," but ultimately remain beyond intention (400). Because design solutions are so intimately local, the act of design, per this line of thinking, must begin not with "critical distance," but "with the immersion of the designer in responsiveness" (414). So, according to Marback, to understand literacy as design is to foreground context, contingency, and attunement. Abstract conceptual knowledge is not useless, of course, but engagement must come first. In other words, for both student and scholar, theory must 
be allowed to arise out of practice.

Taken together, the concepts discussed here hint at a vocabulary that could be used both to research and teach everyday digital media literacy. We can imagine scholarly projects or student assignments that seek to map information ecosystems, or that closely examine behavior at the interface to understand how users design meaning. Such work would attend closely to acts of responsiveness. It would engage in careful, local analysis of everyday digital literacy practices, with an eye towards the various ways bodies, minds, and tools intermesh. What sort of literacy behaviors do digital devices and social media platforms encourage, discourage? How do our means of connection shape how we think, write, read, and relate? Such questions, I'd argue, could mark the start of a discipline-wide effort to understand (and teach) everyday digital media literacy. ${ }^{5}$

At the moment, the above research program is aspirational. Without a doubt, new materialist scholarship has made great strides in theorizing the role of things in the writing process. Likewise, scholars like Sparby have done much to help us understand literacy practices in what Rebecca Tarsa calls "digital participation spaces" (13). That said, writing studies as a whole displays several blind spots that as of yet have prevented the field from making real impact in the area of digital media literacy. First off, writing teacher-scholars remain hesitant to fully engage reading, watching, and other consumption-based literacy practices. As many have noted, for years following a highpoint in the 1980s, the study of reading largely vanished from the composition literature (Keller; Salvatori and Donahue). Though, as indicated by Rodrigue's efforts, interest in digital information consumption is now increasing, we still know very little about how users read, watch, and listen in digital environments.

Composition's lack of interest in cognition also limits our ability to theorize everyday digital media literacy. Reading-writing scholarship, at its highpoint in the 1980s, was heavily influenced by cognitive psychology, but with the social turn, the field's attention famously shifted away from how readers and writers think. Despite stirrings of renewed interest, the topic remains marginalized (Hayes). I believe that this is a problem. To understand and guide digital literacy practices, we need insight into how our tools shape reading and writing, and how these tool-mediated activities work together to create understanding. Such analysis will inevitably involve taking into account both literacy behaviors and cognitive processes. As noted cognitive theorist John Hayes argues, no theory can account for complex literacy practices without considering the interplay of the "cognitive, affective, social, and physical" (qtd. in Keller 30). My claim is that composition has focused too exclusively on the latter items in this list. Thus, while our field's new materialist scholarship is of great value, in order to effectively theorize everyday digital media literacy, we need to look beyond current disciplinary limits.

\section{Literacy at the Interface}

I have argued that to understand or teach everyday digital media literacy, writing scholars need insight into consumption and cognition, insight that, at the moment, our literature can't provide. To fill this gap, I suggest we turn to media studies scholarship. A good place to begin is with the work 
of W. James Potter. The author of a popular series of media literacy textbooks, Potter in Theory of Media Literacy draws on a wide range of empirical research to explicate the theoretical foundations of his pedagogy. Its discussion of our relationship with media, and the ways in which educators can intervene to make this relationship more productive, is perhaps the most in-depth available. ${ }^{6}$

As noted, Potter works at the interface. "Any theory of media literacy," he writes, "must at its core be a theory about how people are affected by the media" (66). This formulation focuses on practice, habits, and the consequences thereof. The underlying idea is that individual thought and action are impacted not only by the content of media consumed, but also by form and means of mediation. Literacy scholars should trace the nature of this impact. Such inquiry, Potter believes, will reveal that some ways of watching TV or using your phone, say, are better than others, in that they lead to more desirable personal and social consequences. Media literacy education, in turn, promotes best practices.

To work at the interface means to pay attention to media, media producer, and media consumer. Indeed, these entities cannot be thought separately. Echoing Barry Wellman, Potter starts from the premise that individuals engage media to satisfy certain needs (to be entertained, informed, etc.). But the interests of media consumers and producers do not always align. In an extended discussion of the nature of mass media, Potter argues that media companies don't so much want conscious awareness as they want mere physical exposure. Through sensory overload and the radical decontextualization of messages, he writes, "we are being trained to tune down our powers of concentration" (14). The goal is "to condition audiences into a ritualistic mode of exposure" (44). Such exposure is ideally thoughtless and extended. Though Potter is speaking here of radio and TV, the parallels with new media are readily apparent. From YouTube videos that play automatically to the variable reward system that makes checking your email or Twitter feed so addictive, our current information environment operates largely along the same lines as traditional mass media. In both cases, the goal is to override conscious thought in order to grab and hold attention (see Harris). More generally, we must remember that all media environments are constructed-and constructed for purposes that may not align with the user's best interests. This idea, Potter suggests, should underlie any theory of media literacy.

Equally important is the idea that there are different types of media engagement. In any media environment, we can't possibly attend to all available sensory data. Instead, we have to apportion our mental resources. Potter differentiates "exposure states" based on the degree of attentiveness, and thus cognitive effort, required. Searching is an active process, motivated by a specific question. It entails conscious attention and is thus the most demanding exposure state. Scanning is less directed and hence less demanding, motivated by a generalized desire rather than a specific question. Screening is less demanding still. In this exposure state, we ignore most of the information present unless given a specific reason to pay attention. Integrally, modern media consumers spend the overwhelming majority of their time in screening mode: there is simply too much mediated information to handle any other way. "To protect ourselves," Potter writes, "we establish a default of avoiding almost all messages" (145).

To illustrate screening-and its prevalence in our lives-Potter presents an example of a trip 
to the supermarket. Here we are confronted with hundreds of thousands of data points. But most are automatically screened out: we will perhaps attend to the labels of half a dozen products. A similar winnowing process occurs whenever we engage with media. Integrally, though, just because we don't consciously engage most television commercials or Facebook posts doesn't mean they don't impact us. In fact, according to Potter, advertising works precisely because, through habituated exposure, marketing claims are able to bypass our critical facilities. "Over time," he writes, echoing cultural studies scholarship, "images, sounds, and ideas build up patterns in our subconscious and profoundly shape the way we think" (10).

As the above indicates, the concept of automaticity is central to Potter's approach. Much of our behavior at the interface is automated, habitual, outside the realm of conscious thought. To my knowledge, writing scholars have yet to consider the role of automaticity in literacy practices. Attention here might be of particular interest to new materialist scholars, because automated behavior is heavily influenced by the design of our tools. As Cory Lawson Ching notes, "sometimes tools have their own agendas" (6). Exactly. And when we act without thought, we often promote those agendas. We might also promote fake news and other digital manipulation efforts.

To illustrate automatized literacy, let's consider the (mis)information circulated by Russiancontrolled Facebook group “The Heart of Texas." Curated by St. Petersburg hipsters, the group's memes and postings are admittedly quite stylish. Upon critical review, though, some seem outlandish. In addition to promoting obviously false and misleading claims about a variety of political issues, The Heart of Texas homepage was riddled with what one reporter describes as "aggressively strange typos" (Michel). Posted content declared that group members are "In Love With Texas Shape," and urged members to proudly share a picture of a giant boot with the caption "Always Be Ready For A Texas Size." Studying these documents, it is clear (in hindsight) that there was something unusual about the group. Still, it had over 250,000 followers, with posts commonly getting hundreds, if not thousands, of likes and shares. Some of this traffic was bot-driven, of course, but a review of the comments section and follower list indicates a large degree of real engagement. How can this be? How could people (e.g. Jerry Herrmann, a patent attorney from Amarillo) not notice, or not care, that something was very obviously not right with The Heart of Texas?

For many humanities scholars, abstract concepts such as ideology or identity would be the go-to explanation for such inexplicable literacy behavior. Perhaps group members were simply blinded by tribal loyalty. Perhaps. But if we follow Potter, we are careful not to naturalize the interface. Instead of looking through Facebook to scholarly abstractions, we examine the nature of the tool at issue and its impact on the human mind and body. In particular, Potter would say that when using a tool like Facebook, we are usually not in "searching" mode. We are not seeking the answer to any specific question. Instead, we want to have fun, express ourselves, or feel a connection with others. The design of the platform encourages non-critical engagement. Unlike traditional mass media, Facebook wants (and needs) us to speak, asking "What's on your mind?" the moment a user logs in. With its colorful, crowded design, strewn with ads and links and engagement options, it doesn't encourage us to listen in any sustained way, though. On each user's "feed," mediated information appears in a torrent. If we join a Facebook group (an act that is itself incentivized), that group's content will, by default, join 
the stream.

So Facebook's design encourages us to maximize our information exposure. By necessity, each user has developed a set of behaviors to manage the platform's demands. For some users, these behaviors originate in conscious reflection. They consider the design of the platform and how their interaction with it can be tailored to best serve their needs. Integrally, though, other users lack the desire or ability to perform this sort of calculation. Instead of actively evaluating and managing information sources, they use cognitive filtering to simply block out content that is not relevant or interesting. They skip from post to post, not consciously attending to much of the information presented. We can imagine that many of the subscribers to The Heart of Texas operated under such a paradigm. They subscribed without much consideration - perhaps because Facebook suggested it. They immediately noticed that much of the group's content was "off" but, rather than unsubscribing, simply proceeded to ignore that content.

Faulty information management can explain the spread of both comically misspelled posts and fake news. Recent empirical evidence indicates that false claims spread fast and far due to their novel nature (Vosoughi, Roy, and Aral). These are the sort of claims that break through a user's automatic filters, get noticed, and thus get shared. If Potter is right, though, the ideas and images that we don't notice are equally important. Beliefs can be shaped by mere physical exposure, remember. Building off this, we must assume that faulty information ecosystem design may actually help lay the groundwork for the acceptance of false claims. Consider the following example. We sign up for Facebook, connect with our friends and family, and join some groups relevant to our interests (Texas, guns, cats, Christ). Our feed is constantly full of anti-Hillary Clinton rhetoric (as is our television and the group chat we share with friends). We are not interested in politics and filter out most of these messages. Still, they exist in the background, creating a reality in which the figure of "Hillary Clinton" is capable of any number of misdeeds. Then The Heart of Texas-whose weird content up until this point we've largely ignored-shares an obviously doctored photo of Clinton shaking hands with Osama Bin Laden. This is striking, novel. We notice and we share, as do hundreds of other proud Texans. Now, if we would go into searching mode, we could easily determine that Clinton had never, in fact, met the leader of Al-Qaida. But nothing in our information ecosystem incentivizes this sort of energy-intensive behavior. As a result, for all intents and purposes, we now believe an obvious falsehood. Automated behavior has set the stage for belief.

The above analysis is clearly speculative; much empirical work (presently ongoing) is needed to verify the extent and precise impact of the literacy behaviors described. That said, in a world where media is everywhere, all evidence indicates that the schemas by which we make sense of reality-and by and through which we make arguments and essays-often don't come to us through conscious attention to authoritative sources. Instead, they are built up over time, through incremental exposure facilitated by automated processes. Recently, scholars such as Jacob Craig have called for a "networkspecific information literacy." He and many other literacy scholars believe that it's no longer sufficient to understand (and teach) literacy through a print-based paradigm. The truth of that claim should now be apparent. But if we accept that mediated information is now everywhere, and our engagement with it is largely automated, how might that change how we teach writing? 


\section{Writing at the Interface}

It seems to me that the first step in designing a writing pedagogy for the age of metastasized media is to rethink the relationship between digital media literacy and writing instruction. In short, I'd suggest that we need to dissolve any perceived boundary between the two. We can only write what we know. As networked individuals, we know through our connections, through the reality we carve out of the mediated flux. Thus, writing instruction must engage students' patterns of connection. It must engage the processes by which they filter and sort mediated information.

Of late, some composition scholars have begun to think in similar terms. Work in the areas of digital reading (Carillo; Rodrigue) and research-based writing (Craig; Singer) is particularly promising. A shared theme is that in a world awash with information, it is no longer sufficient to teach only engagement with academic texts. Instead, our pedagogies should attend to "everyday instances of research" (Craig 37). They should seek to provide students "transferable, user-centered tools" that can be of use both in the library and in daily life (Singer 154). I agree that instruction in non-academic literacy is essential. Students must be taught to use Google productively, judge the credibility of a

"We can only write what we know. As networked individuals, we know through our connections, through the reality we carve out of the mediated flux. Thus, writing instruction must engage students' patterns of connection." website, etc. However, close study of consumption and cognition suggests that we need to go a step further. As my analysis of the situation in Texas sought to make clear, the schemas by which we understand the world are not built primarily through

goal-directed literacy behaviors (what Potter calls "searching"). Instead, the majority of our beliefsespecially about abstract or distant topics-are formed incidentally. They come into being as we pursue pleasure and escape, not knowledge in any direct sense. Writing pedagogy must account for that fact. To this end, the idea of the "information ecosystem" is particularly useful. Each individual dwells within a certain information ecosystem, defined by their habits and patterns of connection. These spaces can be more or less consciously constructed, more or less designed to serve that individual's needs, interests, and values. Writing instruction should help students move towards the "more" side of the spectrum.

Again, Potter's work is instructive. He writes that the "fundamental guiding principle underlying" his approach "is that individuals should be empowered to make their own choices and interpretations" (57). He believes that the modern media environment inherently robs us of choice. In the face of acceleration and information overload, we take shortcuts, trade the good for the fast. We let tools and design do our thinking for us. In an age of "dark patterns", in which website design urges us to spend, in which social media design urges us to engage, and seemingly everything urges us to reveal personal information, such concerns seem oddly prescient. ${ }^{7}$

Assuming we value digital media hygiene, the next question becomes how we should teach 
it. Craig suggests that we develop and share with students "a technological discourse that provides a more complete account of how information is structured, promoted, and commodified within networks" (26). Now, I agree that greater knowledge of network dynamics is needed. But a long history of progressive pedagogies-particularly cultural studies approaches and the critiques thereof-tells us that simply propounding "the facts" is never sufficient (see Berlin; Rickert). Thus, we need teaching methods that make the facts real for students, methods that allow for incorporation and ownership of disciplinary knowledge. Here, I believe that thinking of digital media engagement in terms of design is useful. As we've seen, digital media users can be understood as designers and the navigation of digital networks as a design problem. Solutions to design problems, as Marback reminds us, are found via immersion. This being so, it seems that literacy education, like literacy scholarship, should begin at the interface, at the point where human and non-human meet. It should start with affectivity, responsivity. In practical terms, this is achieved when students make an object of critical inquiry out of their relationship with tools and the degree to which that relationship corresponds with their needs, interests and values. Knowledge about systems and processes and how information is "structured, promoted, and commodified" can grow out of such inquiry.

The idea that literacy education should entail the study of actual practices-noticing-runs throughout recent discussions of literacy in composition studies. Craig himself writes of the importance of "defamiliarizing routine behaviors" (37). In this way, he suggests, we can bring unconscious, habituated behaviors into view so that they can be examined and adjusted. Likewise, Miller and Leon advocate "slow rhetorics," arguing that we must "work with students to slow down our thinking and reflect on our (re)actions" (16). Christina LaVecchia echoes this idea when she writes that digital literacy begins when students can "see their practices as strange." A materialist program for everyday digital media literacy builds on the work of these scholars in positioning noticing as the key pedagogical activity. Students study their digital media practices, the web of connections they weave, and the consequences thereof. Knowledge arises from and returns to those practices.

Because it seeks to give students more control over their tools, and thus their world, the pedagogy I propose might be classified as "liberatory." It's important to note, though, the extent to which a materialist everyday media literacy program differs from earlier critical pedagogies. James Berlin, a critical pedagogue also concerned with media literacy, famously writes that the business of progressive writing teachers should be to "instruct students in signifying practices broadly conceived" (24). In his

"The object of inquiry is not signifying practice,' though. Instead, it is simply practice. Rather than signs and symbols and 'preferred narratives,' students read interfaces-the places where design is actualized." preferred pedagogy (which, I would argue, to this day, represents the default progressive approach), students examine common patterns of symbol use to learn their origin, structure, and social consequences. In the pedagogy I propose, students also create knowledge via the study of everyday activity. The object of inquiry is 
not "signifying practice", though. Instead, it is simply practice. Rather than signs and symbols and "preferred narratives," students read interfaces-the places where design is actualized. And they read not to understand what interfaces mean, but what they do. This involves attention to object, body, and mind, to tools and the thought and behavior they encourage. And the goal of such study is clear from the beginning - to organize one's information ecosystem more effectively. Abstract knowledge about networks or flows or ideology, in other words, is always subordinate to the practical task of construction.

In the above pages, I've argued that writing teachers can and should work to promote everyday digital media literacy. I've argued that we can do so by directing our attention (and that of our students) to the interface, to the places where design is actualized. The goal of such engagement is to help students construct and maintain healthier information ecosystems. As I see it, this goal is best accomplished not through abstract theorizing, but through careful study of digital tools and how they shape thought and behavior. Through study of the local and concrete, literacy researchers and writing students can gain practical insight into patterns of connection, into the filters and sorting mechanisms that, taken as a whole, constitute "networked literacy." Once visible, these systems can be evaluated and adjusted, allowing individuals increased control over their lives and minds.

To close, I'd like to discuss my attempts to deploy these ideas in the classroom. Over the past few years, I've taught versions of the pedagogy proposed at sites in both Europe and the Middle East. My students are typically high-achieving, non-native English-speaking undergraduates. The class is usually presented as an advanced writing course, offered as an English or humanities elective. Overall, student interest and engagement have been remarkable. Digital media these days is like water to a fish: everywhere but unnoticed. I've found that once students begin to notice, a wide array of research and writing opportunities emerge. Students quickly adopt the role of expert and are rarely at a loss for words.

Though developed in an international context, I believe my approach is easily transferable to the American first-year writing (FYW) classroom. In a FYW course focused on essayistic writing, for example, I can imagine students researching digital engagement practices and using their findings to "speak back" to popular commentators. Given the research component, my approach also seems well-suited to the second course in a two-course FYW sequence. In such a context, students could engage the scholarly literature cited in this essay. They could be introduced to concepts such as the interface and information ecosystem and use their immersion in digital media as a site from which to make original contributions to how these concepts are understood. Of course, the ideas in these pages will need to be adapted, rather than adopted. For example, some may feel that the study of personal habits makes for too intrusive of a pedagogy. If so, students could perhaps study the connection patterns of others. The general idea is simply that they attend to tools, habits of tool use, and the ways in which those habits shape how people think and feel, act and react. How best to do this will vary depending on context. 
In my particular context, the study of tools and tool use takes various forms. Students may, for example, track their own digital media habits over the course of a day (or week), asking with whom they connect, how they connect, and what information they share or consume. They may also study tools directly: the design of popular shopping or gaming websites, for example, and the ways in which these environments are constructed to achieve certain ends. The results of such studies are often surprising. One student was shocked to learn that, driven by the variable reward system incorporated into the design of his mobile phone, he sometimes checked his device over 30 times an hour. Another realized, that via exhortations to "Doitdoitdoit", and flashy, convoluted design (a suspected "dark pattern"), she had been persuaded, that very morning, to buy an unnecessarily expensive gaming package. Of course, to work at the interface like these students requires some degree of technical knowledge (a familiarity with the discourse of variable rewards and dark patterns, respectively). But integrally, mastery of technological discourse is not the goal of such work. Instead, the goal is to use existing discourse to create new knowledge grounded in embodied practice. This new knowledge is localized and personalized. It is thus uniquely capable of feeding back into practice and effecting change.

An end-of-semester research project conducted by a student I will call Hamad provides an example of the sort of work one might do at the interface. Upon tracking his digital media habits, Hamad was surprised by the amount of time he spent watching videos on YouTube. He thus decided to research the design of the platform. Online research led him to a Google whitepaper (Covington, et. al) describing YouTube's use of "deep neural networks" and the two-stage process used to generate recommended content. Hamad familiarized himself with this process, then returned to the interface and put what he learned to work. Specifically, he performed an experiment in which he searched for a certain YouTube video (featuring Bruce Lee) on two devices with different prior usage patterns. He then allowed the recommended videos to auto-play. The goal of this experiment, Hamad explained, was to see for himself how the recommendation algorithm functioned. Given each usage pattern, what personal information about him would the machine be able to collect? How would this shape its recommendations?

Interestingly, Hamad found that by the third video the recommended selections had diverged. On one device, the recommended videos were related to martial arts (and in English). On the other, as he put it, they were "completely unrelated, clickbait Arabic videos." In his final essay, Hamad used information gained from the Google whitepaper, as well as class discussions, to explain this disparity. He writes:

An interesting fact to note here is that I have never previously watched Arabic videos on [the first device], but after consulting some friends I was able to conclude that these videos were videos most Arab male teens would click on. The system was successfully able to label me as an Arab male teen, despite the fact I wasn't logged in, and instead ofrecommending videos related to my current selection, it recommended clickbait, meaningless videos to try and make me stay longer on YouTube....

This discovery led Hamad to conclude that YouTube's design may not be operating in his best interests. His experiment, he writes, shows that the platform "is more than happy to recommend any 
video that will make you spend more time online, regardless of the content and whether it is useful or not." Here we see knowledge making of the most potent sort. Abstract ideas about data privacy, sorting algorithms and profit motive are grounded in lived experience and thus made real. As such, Hamad comes to better understand the mechanisms that work behind the scenes to shape his information exposure. Simply put, he catches a glimpse of the constitute structure of his information ecosystem. Once visible, I'd argue, that structure can be reworked. Indeed, Hamad later expressed a desire to manage his YouTube account more actively as to avoid "clickbait." My claim is that close attention to the interface-to our tools and the thought and behavior they encourage-is a potent way to facilitate this sort of active media engagement.

It's important to note the self-directed nature of Hamad's learning activities. Though the class did discuss recommendation algorithms (via a TED Talk by Eli Pariser), I did not guide him to the Google whitepaper. I did not suggest he research YouTube nor help him design his experiment. Instead, he made these choices himself based on his interests and experience. Whether we know it or not, we each have extensive experience at the interface. As Hamad's work illustrates, the pedagogy I propose is uniquely able to activate otherwise latent knowledge.

It's also important to note, especially in light of the recent "techlash," that an everyday digital media literacy program must involve more than simply proving to students that they're being manipulated. Indeed, many of my students, upon evaluating behavior at the interface, identify ways in which digital media technology improves their lives or the lives of others. An end-of-semester project by Igor offers an illustration. For his topic, Igor researched massively multiplayer online roleplaying games, specifically World of Warcraft (WoW). He examined media reports that video games negatively affect mental health, along with empirical research about the social behavior of gamers. Drawing on his own experience, he then considered the design of WoW and the human impact thereof. He reports that the objectives set by the game encourage semi-stable groupings called "guilds." Because "co-guilders" play together over extended periods of time, and because the game allows for real-time chat, guild members often establish close personal relationships. Interestingly, these relationships can drive game usage. In describing his gaming activities, Igor writes:

Most of my time in the game I was playing with my co-guilders. At the beginning we were just doing something on purpose together, [the game] activities held us together. But after several month I started logging in just to chat with my co-guilders. So, my relationships pushed me to do something in the game.

In the above passage, Igor reflects on his behavior at the interface. Like Hamad, he makes abstract knowledge real by grounding it in lived experience. In doing so, he too engages the web of connections that shapes how he thinks, feels, and acts. Igor's methodology is different (reflection vs. empirical research), as is his conclusion. While acknowledging that the company that makes WoW benefits from his increased gameplay, Igor decides that he is satisfied with the deal he has struck. He argues that playing WoW, in addition to allowing for new friendships, taught him valuable social skills, such as the ability to "interact with strangers" and "manage little groups of people." Ultimately, he concludes that video games can improve mental health.

Igor's conclusion is well-argued. More important, though, is the work that he did to reach it. He 
considered his tools, himself, and the relationship between the two. He then weighed the extent to which his patterns of tool use correspond with his needs, interests, and values. This is a calculation, I'd suggest, that everyone should be encouraged to perform.

An odd characteristic of technology is that as it becomes more ubiquitous, it becomes less interesting. Few scholars, for example, study word processing programs or hypertext anymore, though most of us use these tools every day. Overall, my claim has been that to understand and guide networked literacy, we need to reverse this dynamic. We need to attend to social media, smart phones, email, and other tools that have become so engrained in our daily lives as to become invisible. But, of course, writing teachers are not programmers or engineers. We are, most of us anyway, humanists. Thus we best engage these technologies not on the level of code or circuitry, but on the level of human thought and behavior. How do our tools shape how we think, write, read, and relate? How can we design better patterns of engagement? If my experience is any indication, the writing classroom is an ideal place to ask such questions. Now, of course, college writing classes that engage everyday digital media literacy practices can't single-handedly save democracy. But they do represent a tangible, imminently practical step our field can take to address one of the major problems threatening it. Simply put, when tool use is thoughtless and information ecosystems poorly designed, networked individuals cannot be informed and engaged. They cannot be good citizens. I claim that by directing attention to the interface, to the point where the human and non-human meet, we can reverse this dynamic. In doing so, we can help our students become not just better writers, but the type of writers our world needs most. 


\section{NOTES}

${ }^{1}$ Other than arguing that "digital media literacy" entails the ability to design healthy information ecosystems, I won't endeavor to present a more detailed definition of the term. It seems to me that one can be called "digital media literate" whenever they can use digital media tools to achieve their goals. The specific skills and behaviors involved vary based on context.

2 Individuals have always had to weigh competing data points and information sources, of course. The key difference now, though, according to Wellman, is that there is more potential data, more sources of data, and fewer agreed upon rules to parse that data.

${ }^{3}$ In making this argument I align with a small but vocal group of scholars currently arguing for more attention to reading in the writing classroom (see Keller, Carillo, Horning). As Daniel Keller puts it, reading and writing are "literacy components"-we can't teach one without the other (36). I totally agree. We also need to recognize, though, that much of the reading our students do might not register as "reading" in the traditional sense.

${ }^{4}$ I use this term simply to refer to recent writing studies scholarship that foregrounds the role of tools, spaces, bodies, and other physical objects in literacy practices. Such work doesn't necessarily bear any relationship to the philosophical school of new materialism, also called "speculative realism," associated with thinkers such as Graham Harman and Quinton Millexioux.

${ }^{5}$ Along with a move towards materialism, for the past twenty years or so literacy studies has favored what Beth Daniell calls "little narratives" - studies that examine literacy behaviors among certain subgroups (403). College Composition and Communication's recent symposium on literacy, edited by Thomas Miller, operates largely in this vein. Certainly, readings of these narratives from a materialist perspective have much to offer the networked literacy project.

${ }^{6}$ Published in 2004, Theory of Media Literacy deals exclusively with mass media. Potter's ideas, therefore, must be translated rather than directly applied.

${ }^{7}$ See www.darkpatterns.org; also www.humanetech.com. 


\section{WORKS CITED}

Arola, Kristin. “The Design of Web 2.0: The Rise of the Template, The Fall of Design." Computers and Composition, vol. 27, no. 1, 2010, pp. 4-14.

Baron, Naomi. Words Onscreen: The Fate of Reading in a Digital World. Oxford UP, 2015.

Berlin, James A. "Poststructuralism, Cultural Studies, and the Composition Classroom: Postmodern Theory in Practice." Rhetoric Review, vol. 11, no. 1, 1992, pp. 16-33.

Bertrand, Natasha. "Russia Organized 2 Sides of a Texas Protest and Encouraged 'Both Sides to Battle in the Streets." Business Insider, Nov 1, 2017.

Brandt, Deborah, and Katie Clinton. "Limits of the Local: Expanding Perspectives on Literacy as a Social Practice." Journal of Literacy Research, vol. 34, no. 3, 2002, pp. 337-56.

Byrd, Antonio. "Between Learning and Opportunity: A Study of African American Coders' Networks of Support.” Literacy in Composition Studies, vol. 7, no. 2, 2019, pp. 31-55.

Carillo, Ellen C. "Navigating This Perfect Storm Teaching Critical Reading in the Face of the Common Core State Standards, Fake News, and Google.” Pedagogy, vol. 19, no. 1, 2019, pp. 135-59.

Ching, Kory Lawson. "Tools Matter: Mediated Writing Activity in Alternative Digital Environments." Written Communication, vol. 35, no. 3, 2018, pp. 344-75.

Cooper, Marilyn M. “The Ecology of Writing.” College English, vol. 48, no. 4, 1986, pp. 364-75.

Covington, Paul, Jay Adams, and Emre Sargin. "Deep Neural Networks for YouTube Recommendations." RecSys '16: Proceedings of the 10th ACM Conference on Recommender Systems, ACM, 2016, pp. 191-98.

Craig, Jacob W. "Navigating a Varied Landscape: Literacy and the Credibility of Networked Information." Literacy in Composition Studies, vol. 5, no. 2, 2017, pp. 24-42.

Daniell, Beth. "Narratives of Literacy: Connecting Composition to Culture." College Composition and Communication, vol. 50, no. 3, 1999, pp. 393-410.

Deuze, Mark. “Media Life." Media, Culture \& Society, vol. 3, no. 1, 2011, pp. 137-48.

Glenn, Mike. "Dozens Turn Out to Support Houston Muslims." Houston Chronicle, May 21, 2016, https://www.chron.com/news/houston-texas/houston/article/Dozens-turnout-to-supportHouston-Muslims-7926843.php.

Harris, Tristan. "How Technology Hijacks People’s Minds—-from a Magician and Google's Design Ethicist." medium.com, 19 May 2016, https://medium.com/thrive-global/how-technologyhijacks-peoples-minds-from-a-magician-and-google-s-design-ethicist-56d62ef5edf3.

Hawisher, Gail E., et al. "Becoming Literate in the Information age: Cultural Ecologies and the Literacies of Technology." College Composition and Communication, vol. 55, no. 4, 2004, pp. 642-92.

Hayes, John R. “Are Cognitive Studies in Writing Really Passé?” Contemporary Perspectives on Cognition and Writing, edited by Patricia Portanova, J. Michael Rifenburg, and Duane H. Roen, WAC Clearinghouse, 2018, pp. vii-xv.

Horning, Alice. "Neuroscience of Reading: Developing Expertise in Reading and Writing." Contemporary Perspectives on Cognition and Writing, edited by Patricia Portanova, J. 
Michael Rifenburg, and Duane H. Roen, WAC Clearinghouse, 2018, pp. 79-94.

Jenkins, Henry. “The Cultural Logic of Media Convergence." International Journal of Cultural Studies, vol. 7, no. 1, 2004, pp. 33-43.

Keller, Daniel. Chasing Literacy: Reading and Writing in an Age of Acceleration. Utah State UP, 2013. LaVecchia, Christina. "Toward a Pedagogy of Materially Engaged Listening." Composition Forum, vol. 35, 2017.

Marback, Richard. "Embracing Wicked Problems: The Turn to Design in Composition Studies." College Composition and Communication, vol. 61, no. 2, 2009, pp. 397-419.

Micciche, Laura. "Writing Material.” College English, vol. 76, no. 6, 2014, pp. 488-505.

Michel, Casey. "How Russia Created the Most Popular Texas Secession Page on Facebook," Extra Newsfeed, 8 Sept. 2017, extranewsfeed.com/how-russia-created-the-most-popular-texassecession-page-on-facebook-fd4dfd05ee 5c.

Miller, Thomas, and Adele Leon. "Introduction to Special Issue on Literacy, Democracy, and Fake News: Making It Right in the Era of Fast and Slow Literacies." Literacy in Composition Studies, vol. 5, no. 2, 2017, pp. 10-23.

Miller, Thomas, editor. "Symposium: What Will We Have Made of Literacy?" College Composition and Communication, vol. 69, no. 3, 2018, pp. 494-533.

National Council of Teachers of English. "Definition of Literacy in a Digital Age." National Council of Teachers of English, 2019, ncte.org/statement/nctes-definition-literacy-digital-age/.

New London Group. “A Pedagogy of Multiliteracies: Designing Social Futures.” Harvard Educational Review, vol. 66, no. 1, 1996, pp. 69-93.

Pariser, Eli. “Beware of Online Filter Bubbles.” TED, March 2011, www.ted.com/talks/eli_pariser_ beware_online_filter_bubbles.

Portanova, Patricia, J. Michael Rifenburg, and Duane H. Roen, editors. Contemporary Perspectives on Cognition and Writing. WAC Clearinghouse, 2018.

Potter, W. James. Theory of Media Literacy: A Cognitive Approach. Sage Publications, 2004.

Prior, Paul, and Jody Shipka. "Chronotopic Lamination: Tracing the Contours of Literate Activity." Writing Selves, Writing Societies: Research from Activity Perspectives, edited by Charles Bazerman and David R. Russell, WAC Clearinghouse, 2003, pp. 180-238.

Purdy, James P. "The Changing Space of Research: Web 2.0 and the Integration of Research and Writing Environments." Computers and Composition, vol. 27, no. 1, 2010, pp. 48-58.

Rainie, Lee, and Barry Wellman. Networked: The New Social Operating System. MIT P, 2012.

Rickert, Thomas Joseph. Acts of Enjoyment: Rhetoric, Žižek, and the Return of the Subject. U of Pittsburgh P, 2007.

Rodrigue, Tanya. "Digital Reading Genre Awareness as a Tool for Reading Comprehension." Pedagogy, vol. 17, no. 2, 2017, pp. 235-57.

Rule, Hannah. "Writing's Rooms." College Composition and Communication, vol. 69, no. 3, 2018, pp. 402-32.

Salvatori, Mariolina, and Patricia Donahue. "Guest Editors' Introduction: Guest Editing as a Form of Disciplinary Probing." Pedagogy, vol. 16, no. 1, no. 2015, pp. 1-8. 
Selber, Stuart. Multiliteracies for a Digital Age. Southern Illinois UP, 2004.

Selfe, Cynthia L., and Richard J. Selfe. "The Politics of the Interface: Power and Its Exercise in Electronic Contact Zones." College Composition and Communication, vol. 45, no. 4, 1994, pp. 480-504.

Singer, Sarah A. "Embracing Wildcard Sources: Information Literacy in the Age of Internet Health." College English, vol. 82, no. 2, 2019, pp. 152-72.

Sparby, Erika M. "Digital Social Media and Aggression: Memetic Rhetoric in 4chan's Collective Identity." Computers and Composition, vol. 45, 2017, pp. 85-97.

Stewart, Mary. "The Social Practice of Literacy in the Internet Age: Multimedia Composition, Information and Collaboration." Computers and Composition Online, 2014, cconlinejournal. org/fall14/social/index.html.

Syverson, Margaret. The Wealth of Reality: An Ecology of Composition. Southern Illinois UP, 1999.

Tarsa, Rebecca. "Upvoting the Exordium: Literacy Practices of the Digital Interface." College English, vol. 78, no. 1, 2015, pp. 12-33.

Vosoughi, Soroush, Deb Roy, and Sinan Aral. "The Spread of True and False News Online." Science, vol. 359, 2018, pp. 1146-51.

Wellman, Barry. "Little Boxes, Glocalization, and Networked Individualism." Kyoto Workshop On Digital Cities, Springer, 2001, pp. 10-25.

Williams, Bronwyn. "Having a Feel for What Works: Polymedia, Emotion, and Literacy Practices with Mobile Technologies." Social Media and Social Writing: Publics, Presentations and Pedagogies, edited by Douglas M. Walls and Stephanie Vie, WAC Clearinghouse, 2018, pp. 127-43.

Wysocki, Anne Frances, and Julia I. Jasken. "What Should be an Unforgettable Face...." Computers and Composition, vol. 21, no. 1, 2004, pp. 29-48. 